\title{
Ophthalmic features and visual prognosis in the Treacher-Collins syndrome
}

\author{
Richard W Hertle, Sule Ziylan, James A Katowitz
}

\begin{abstract}
The ocular findings and visual prognosis were reviewed in 24 patients with the TreacherCollins syndrome who were evaluated in the craniofacial clinic in the Division of Pediatric Ophthalmology at Children's Hospital of Philadelphia between 1980 and 1991. All patients had some abnormality. Vision loss was present in 37\% of patients. Amblyopia was present in $33 \%$, significant refractive errors were present in $58 \%$, and anisometropia was documented in $17 \%$. Strabismus was present in $37 \%$ and significant lid and adnexal abnormalities were seen in $96 \%$. The prognosis for normal vision in at least one eye is good but vision loss secondary to amblyopia is more resistant to treatment owing to other medical problems and social concerns.
\end{abstract}

(Brf Ophthalmol 1993; 77: 642-645)

The Treacher-Collins syndrome (TCS) is an autosomal dominant facial malformation with variable penetrance and is also known as zygoauromandibular dysplasia or mandibulofacial dysostosis (MFD). ${ }^{1-4}$ This bilateral anomaly represents a cluster of malformations resulting in zygomatic, temporoaural, and mandibular dysplasia. It was first reported by Berry in $1889^{5}$ in a mother and daughter. Rogers, ${ }^{3}$ and Franceschetti and Klein ${ }^{1}$ further clarified the clinical findings in their case reports. Most patients with TCS are of normal intelligence, but may be socially affected owing to their appearance or appear retarded secondary to hearing loss.

TCS is characterised by hypoplasia and retrusion of the malar region, obliteration of the frontonasal angle, and a receding chin. Protrusion of the nose and maxilla may produce an enophthalmic appearance. The inferior lateral angle of the orbit is defective and the superolateral part of the orbit is displaced caudally giving the orbit an egg shaped appearance. The orbital contents appear displaced into the deficiency created by the malar hypoplasia ${ }^{1-6}$ (Fig 1).

Ocular abnormalities include pseudocolobomas (hypoplastic subcutaneous tissue, and muscle) and true colobomas (full thickness absence of tissue) of the lids, especially inferolaterally, canthal dystopia, orbital lipodermoids, limbal dermoids, and occasional microphthalmos and anophthalmos..$^{\text {s-9 }}$ Cataracts, lacrimal duct atresia, pupillary ectopia, dystichiasis, and uveal colobomas have all been reported..$^{5-9}$ Strabismus has been reported in several forms including esotropia, exotropia, Duane's syndrome, and cranial nerve palsies. ${ }^{5-9}$

A large variety of ear abnormalities can be present. Respiration can be affected by sinus and

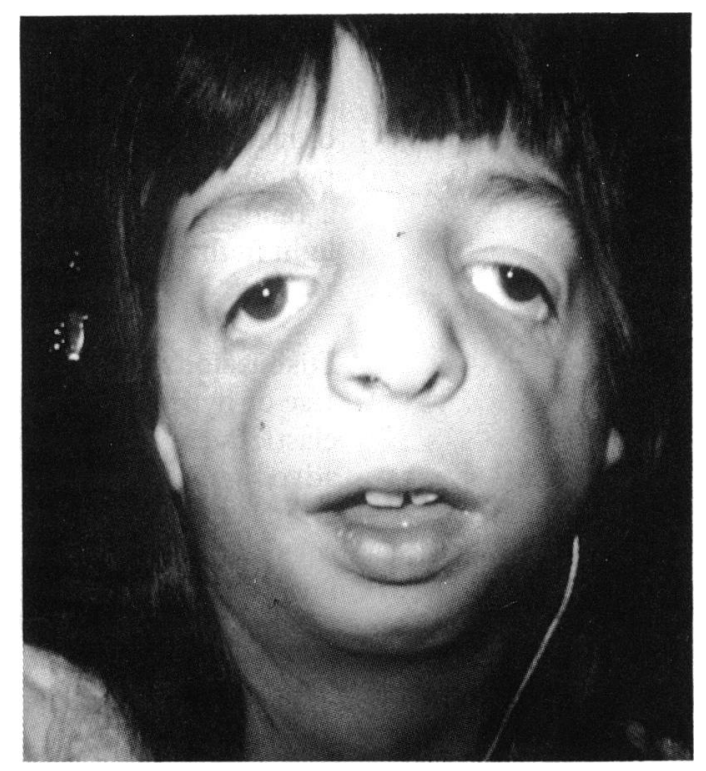

Figure 1 This patient has a severe form of Treacher-Collins syndrome.

choanal atresia, and lingual obstruction because of mandibular retrusion. ${ }^{8-11}$ Cleft lip and palate, enlarged sphenoid bone fissures, and skeletal and cranial synostoses are other reported abnormalities. ${ }^{12-13}$ This report summarises our experience managing 24 patients as part of the craniofacial clinic in the division of ophthalmology at the Children's Hospital of Philadelphia.

\section{Methods}

The craniofacial clinic is a monthly multispecialty clinic at the Children's Hospital of Philadelphia. Patients have an ophthalmic examination as part of a day long process which includes evaluation by many paediatric subspecialties including: plastic and reconstructive surgery, neurosurgery, oral and maxillofacial surgery, dentistry, genetics, ophthalmology, otolaryngology, psychiatry/psychology, social work, and speech and hearing. This group meets at the end of the clinic day to discuss patient evaluations and proposed treatments.

The clinical records of 329 patients seen for a complete ocular examination from 1980 to 1991 have been entered into a computerised database in the Division of Pediatric Ophthalmology. Data include name, ages at first and most recent examinations, craniofacial diagnosis, best and worst visual acuities, amblyopia, pupillary abnormalities, motility disturbances, results of fusion testing, intraocular, disc or retinal abnormalities, lid and adnexal abnormalities, cycloplegic refraction (40 minutes after $1 \%$ cyclopentolate (Cyclogyl) in children older than 1 
Table 1 Clinical characteristics of 24 patients with Treacher-Collins syndrome

\begin{tabular}{|c|c|c|c|c|c|}
\hline$P T$ & $V A$ & Refraction & Strabismus & HX amblyopia & Lid/adnexal abnormality \\
\hline 1 & $\begin{array}{l}20 / 30 \text { OD } \\
20 / 20 \text { OS }\end{array}$ & $\begin{array}{l}+1.25 \\
+1.75\end{array}$ & Ortho & No & Dacryostenosis OU, pseudocoloboma OU \\
\hline 2 & $\begin{array}{l}20 / 20 \text { OD } \\
20 / 20 \text { OS }\end{array}$ & $\begin{array}{l}-1.00+0.75 \times 90 \\
-0.50+0.50 \times 90\end{array}$ & Ortho & No & Ptosis, pseudocoloboma, telecanthus, epicanthus OU \\
\hline 3 & $\begin{array}{l}20 / 20 \text { OD } \\
20 / 20 \text { OS }\end{array}$ & $\begin{array}{l}+2 \cdot 50 \\
+4 \cdot 50\end{array}$ & Ortho & No & Canthal dystopia OU, telecanthus, epicanthus OU \\
\hline 4 & $\begin{array}{l}\text { F\&F OD } \\
\text { F\&F OS }\end{array}$ & $\begin{array}{l}\text { Plano } \\
+0.50\end{array}$ & XT & No & Lower lid coloboma OU \\
\hline 5 & $\begin{array}{l}20 / 20 \text { OD } \\
20 / 60 \text { OS }\end{array}$ & $\begin{array}{l}-1.00+0.75 \times 12 \\
-0.50+1.00 \times 160\end{array}$ & OALSO & OS & Ptosis OU \\
\hline 6 & $\begin{array}{l}20 / 20 \text { OD } \\
20 / 20 \text { OS }\end{array}$ & $\begin{array}{l}+0.75 \\
+0.25\end{array}$ & Ortho & No & Lower lid coloboma OU \\
\hline 7 & $\begin{array}{l}20 / 30 \text { OD } \\
20 / 30 \text { OS }\end{array}$ & $\begin{array}{l}+0.50 \\
-0.50+1.00 \times 60\end{array}$ & Ortho & No & Dacryostenosis OU, pseudocoloboma OU \\
\hline 8 & $\begin{array}{l}20 / 20 \text { OD } \\
20 / 25 \text { OS }\end{array}$ & $\begin{array}{l}+1 \cdot 50 \\
+1 \cdot 50\end{array}$ & $\mathrm{XT}$ & No & Canthal dystopia OU, lower lid coloboma OU \\
\hline 9 & $\begin{array}{l}20 / 20 \text { OD } \\
20 / 20 \text { OS }\end{array}$ & $\begin{array}{l}-4 \cdot 50+1 \cdot 50 \times 180 \\
-3 \cdot 50+2 \cdot 75 \times 75\end{array}$ & $\begin{array}{l}\text { CN VI palsy, } \\
\text { LHT }\end{array}$ & OD & Pseudocoloboma OU, canthal dystopia OU \\
\hline 10 & F\&F OD & $\begin{array}{l}+0.50 \\
+0.50\end{array}$ & Ortho & No & $\begin{array}{l}\text { Dacryostenosis OU, canthal dystopia OU, absent inferio } \\
\text { systems }\end{array}$ \\
\hline 11 & $\begin{array}{l}20 / 20 \text { OD } \\
20 / 40 \text { OS }\end{array}$ & $\begin{array}{l}+1.00+0.25 \times 31 \\
+1.75+0.50 \times 45\end{array}$ & ET & OS & Canthal dystopia OU \\
\hline 12 & $\begin{array}{l}20 / 20 \text { OD } \\
20 / 20 \text { OS }\end{array}$ & $\begin{array}{l}+1.00 \\
+1.00+1.00 \times 90\end{array}$ & Ortho & No & $\begin{array}{l}\text { Canthal dystropia OU, pseudocoloboma RLL, } \\
\text { coloboma RLL }\end{array}$ \\
\hline 13 & $\begin{array}{l}20 / 20 \text { OD } \\
20 / 20 \text { OS }\end{array}$ & $\begin{array}{l}+1.25 \\
+1.25\end{array}$ & Ortho & No & Pseudocoloboma OU, canthal dystopia OU \\
\hline 14 & $\begin{array}{l}20 / 25 \text { OD } \\
20 / 25 \text { OS }\end{array}$ & $\begin{array}{l}-0.75+1.00 \times 135 \\
-0.50+0.50 \times 45\end{array}$ & Ortho & OD & Pseudocoloboma OU \\
\hline 15 & $\begin{array}{l}\text { CSM } \\
\text { CSM }\end{array}$ & $\begin{array}{l}-1.00+1.00 \times 175 \\
-2.00+1.00 \times 45\end{array}$ & XT, RHT & No & None \\
\hline 16 & $\begin{array}{l}20 / 20 \text { OD } \\
20 / 20 \text { OS }\end{array}$ & $\begin{array}{l}+2.75+3.00 \times 150 \\
+2.00+3.25 \times 14\end{array}$ & Ortho & No & Pseudocoloboma OU \\
\hline 17 & $\begin{array}{l}\text { CSM OD } \\
\text { CSM OS }\end{array}$ & $\begin{array}{l}-1 \cdot 25+1 \cdot 75 \times 140 \\
-3 \cdot 00+2 \cdot 25 \times 40\end{array}$ & Ortho & No & Pseudocoloboma OU \\
\hline 18 & $\begin{array}{l}\text { 20/20 OD } \\
20 / 20 \text { OS }\end{array}$ & $\begin{array}{l}+0.75 \\
+0.25\end{array}$ & Ortho & No & Coloboma OU, entropion OU, trichiasis OU \\
\hline 19 & CF OD & $\begin{array}{l}+4.00+1.00 \times 45 \\
+1.25\end{array}$ & XT & OD & Ptosis OU, lower lid coloboma OU \\
\hline 20 & $\begin{array}{l}20 / 200 \text { OD } \\
20 / 200 \text { OS }\end{array}$ & $\begin{array}{l}+0.50 \\
+0.75\end{array}$ & Ortho & No & Canthal dystopia OU, (CVI) pseudocoloboma OU \\
\hline 21 & $\begin{array}{l}20 / 30 \text { OD } \\
20 / 40 \text { OS }\end{array}$ & $\begin{array}{l}-1.00+0.75 \times 135 \\
-1.00+0.75 \times 60\end{array}$ & $\begin{array}{l}\text { V-XT, } \\
\text { OAIO OU }\end{array}$ & No & Pseudocoloboma OU \\
\hline 22 & $\begin{array}{l}20 / 40 \text { OD } \\
20 / 25 \text { OS }\end{array}$ & $\begin{array}{l}-2 \cdot 00+3.00 \times 135 \\
-1 \cdot 75\end{array}$ & Ortho & OD & Ptosis OU, canthal dystopia OU \\
\hline 23 & $\begin{array}{l}20 / 30 \text { OD } \\
20 / 40 \text { OS }\end{array}$ & $\begin{array}{l}+2 \cdot 00 \\
+2 \cdot 00\end{array}$ & Ortho & No & Canthal dystopia \\
\hline 24 & $\begin{array}{l}\text { 20/30 OD } \\
20 / 50 \text { OS }\end{array}$ & $\begin{array}{l}+1.25+3.00 \times 165 \\
+0.75+5.00 \times 20\end{array}$ & ET & OS & Canthal dystopia pseudocoloboma OU \\
\hline
\end{tabular}

VA=visual acuity; $O D=$ right eye; $O S=$ left eye; $O U=$ both eyes; $C S M=$ central, steady, and maintained gaze; Ortho=orthophoria; $\mathrm{XT}=$ exotropia; $\mathrm{OALSO}=$ overaction of left superior oblique; CN VI = cranial nerve VI; $\mathrm{LHT}=$ left hypertropia; $\mathrm{RHT}=$ right hypertropia; $\mathrm{ET}=$ esotropia; $\mathrm{F} \& \mathrm{~F}=$ fixes and follows; $\mathrm{CVI}=$ central visual impairment; $\mathrm{V}-\mathrm{XT}=$ 'V' pattern exotropia; $\mathrm{OAIU}=$ overaction of the inferior oblique

year of age and $0.5 \%$ under 1 year of age), and type of strabismus procedures and results.

Fifty one per cent of these patients had craniofacial stenoses, $25 \%$ had clefting syndromes, $17 \%$ had other varied and often singular craniofacial deformities, $7 \%$ had orbital tumours or trauma and were evaluated by the entire team.

The data included in this report are from all patients who were examined in the craniofacial clinic between 1980 and 1991 with the diagnosis of TCS. Patients who had other first and second branchial arch syndromes (for example, Goldenhar's, facial microsomia) or clefting syndromes (for example, Stickler's syndrome, typical orofacial ocular clefts) were excluded from analysis. All data used for this analysis were accumulated from one or multiple examinations of each patient. Twenty patients were examined on more than one occasion and four were examined once. If an ocular abnormality was present at any examination the date of onset and follow up treatments and results were recorded. The follow up on the 20 patients with repeat examinations ranged from 1 to 12 years with an average of 4.5 years. All abnormalities reported were diagnosed during either their initial or subsequent evaluations in the Division of Pediatric Ophthalmology.

Ametropic refractive errors were defined as hyperopia greater than $+2 \cdot 00$ sphere, myopia greater than -0.75 sphere, or astigmatism greater than 0.75 dioptres at any examination. Anisometropia was defined as greater than 1.50 dioptres difference between the eyes in any meridian at any examination.

\section{Results}

Twenty four of $329(7 \%)$ patients or $17 \%$ of patients excluding craniofacial stenoses, tumours, and trauma were diagnosed with TCS. Patient age at first examination ranged from $2 \cdot 5$ months to 20 years (median $2 \cdot 7$ years). Fourteen patients were male.

All patients examined in this study had some ocular and adnexal abnormality (Table 1). Refractive errors were present in $14(58 \%)$ patients. Five patients had anisometropia, 13 had mixed astigmatism, and one had simple myopia.

Ten eyes $(21 \%)$ in nine $(37 \%)$ patients had or have abnormal vision. Eight eyes in eight patients (33\%) had amblyopia at some time during their evaluation and follow up as part of the craniofacial clinic. One patient having 20/200 visual acuity bilaterally by Teller acuity card testing had central visual impairment (post-chiasmal dysfunction of unknown aetiology) and was also 
mentally retarded (patient 20). The visual acuities listed in the table are those at the last examination. All patients with amblyopia have had or are currently receiving treatment. This consisted of refractive correction when indicated combined with occlusion therapy. At the time of this report total treatment periods ranged from 3 months to 4 years, with a median of 21 months. Six of the eight patients did not have equal visual acuities at their most recent examination. All these patients had poor compliance with the instructed occlusion regimen.

Strabismus was diagnosed in nine (37\%) patients. There were two patients with esotropia, five with exotropia, one with a cranial nerve six palsy, and one with overaction of the left superior oblique muscle. One patient had a $\mathrm{V}$ pattern and associated inferior oblique muscle overaction in addition to the exotropia (Table 1).

Except for one patient with bilateral pseudopapilloedema secondary to buried drusen, no intraocular abnormalities were observed.

Lid and adnexal eye disorders were present in 24 patients $(100 \%)$ (Table 1). Canthal dystopia was present in 24 patients, dacryostenosis in three patients, blepharoptosis in six patients, lateral lower lid true coloboma in six patients, and pseudocolobomas in 13 patients. Entropion and trichiasis were each present in one patient.

\section{Discussion}

The TCS belongs to a group of craniofacial anomalies having in common maldevelopment of the first and second branchial arches. ${ }^{1-414-16}$ Characteristic clinical, familial, and chromosomal findings justify separation of this syndrome from other abnormalities in development of the first and second branchial arches. The others include facial clefting syndromes, Goldenhar's syndrome, facial microsomias, Miller's syndrome (digit and limb abnormalities, and acrofacial dysostosis), and Nager's syndrome (radial limb deficiencies). ${ }^{15} 16$

Franceschetti and Klein ${ }^{1}$ suggested a classification system consisting of five clinical forms: (1) the complete form, having all known features, (2) the incomplete form, presenting variably with less severe ear, eye, zygoma, and mandibular abnormalities, (3) the abortive form, in which only the lower lid pseudocoloboma and zygoma hypoplasia are present, (4) the unilateral form, with the anomalies limited to one side of the face regardless of severity, and (5) the atypical form or incomplete form combined with other abnormalities not usually part of the typical syndrome.

They reported that the most common forms were the typical and atypical (1 and 5) varieties. $^{12412}$ The existence of the unilateral form has been challenged and may actually represent a type of facial microsomia which is often unilateral and shares many common features with TCS. ${ }^{17}{ }^{18}$ This classification system represents a spectrum of variability in the clinical presentation of this malformation. This system is presented for historical purposes as the functional and cosmetic consequences and treatment options do not depend on one or another form.

The aetiology of the facial defects in TCS are unknown. Recent evidence suggests that the genetic defect responsible for TCS maps to the long arm of chromosome 5. ${ }^{19}$ Postulated consequences of this genetic defect may cause a complete absence of embryonic malar bone centres or their outgrowth, or hypoplasia of bones or parts of bones after development. ${ }^{19-21}$ There is experimental and embryological evidence which suggests that abnormal neural crest migration as early as 4 months' gestation may be related to the defects of TCS. ${ }^{20-22}$ The genetic defect in TCS may be responsible for creating this deformity by disrupting migration of these neural crest cells. ${ }^{20}$ It is believed that these defects occur before the $17 \mathrm{~mm}$ crown to rump length (17-20 weeks). ${ }^{19-21}$ In other work with animal embryos abnormal stapedial artery blood supply during the sixth week of embryogenesis can produce ear and facial abnormalities similar to TCS. ${ }^{20}$ In this model the associated overlying soft tissue and muscular defects are the results of underlying aberrant bony maldevelopment.

Abnormal lid and adnexal morphology and function, ocular motility problems, refractive errors, and amblyopia are the abnormalities which most frequently require treatment. Specific treatment of associated ophthalmic abnormalities in patients with craniofacial anomalies follow similar principles utilised in patients without the anomalies.

Lid malpositions, colobomas, and pseudocolobomas are usually treated surgically. Inadequate underlying bone in the lateral canthal area presents a unique challenge. Lateral canthal dystopia can be repaired at the time of maxillary reconstruction but the maxillary hypoplasia may need several staged procedures. It is sometimes advantageous to postpone definitive lateral canthal reconstruction until these procedures have been completed.

Motility problems are treated after amblyopia therapy and correction of refractive errors. Surgical treatment of strabismus proceeds according to the strabismus diagnosis and not necessarily delayed until other craniofacial surgery is performed. We prefer to use the fornix incision in approaching the muscle because is it easier to examine all the muscle insertions. Anomalous insertions are seen with increased frequency in patients with other craniofacial malformations and in some instances may contribute to the type of strabismus. ${ }^{23}$ Discovering anomalous muscle position or number during surgery may influence the surgical plan.

The percentage of patients with vision loss (37\%) and strabismus (37\%) in this series is higher than in the general paediatric population. Other series do not report the vision in their patients making comparison between series difficult. ${ }^{357}$ The overall visual prognosis in these patients is favourable although there is a much higher incidence of unilateral vision loss. The most common reason for this is amblyopia. As in patients with other craniofacial syndromes this is due to a combination of factors which are independently amblyogenic. ${ }^{2+25}$ Refractive errors, anisometropia, strabismus, and ptosis combined to various degrees were responsible 
for the amblyopia in our patients. No patients had structural problems of the globe which contributed to their vision loss. Patient 20 had post-chiasmal visual dysfunction (central visual impairment) which, by history, was the result of a perinatal anoxic insult. Of the eight patients with amblyopia, equal vision was only obtainable in two at the last examination. This emphasises compliance difficulties in these patients. Oral and auricular function may also be affected and cosmetic deformities in these patients can be severe. Because of this the patient and family may be more concerned with the correction of these defects. This contributes to the poor prognosis of amblyopia therapy.

Ocular abnormalities are frequent associations of major craniofacial malformations. ${ }^{7226}$ In general the eye, orbit, and adnexa are more likely to be involved in deformities affecting the cranium and upper face. ${ }^{8}$ Abnormalities of the lower face, jaw, maxilla, and oral structures are more often observed without associated ocular involvement. ${ }^{911}$ Previous reports of the ocular abnormalities associated with the TCS have concentrated on the deformities of the skin and soft tissue structures affected by the underlying bony deformity. ${ }^{5911}$

This report summarises the ocular and visual consequences of a malformation related to but not directly affecting the eye. This emphasises the intimate developmental relationship of all cranial and facial structures during embryogenesis. Visual acuity, amblyopia and its response to treatment, refractive errors, strabismus, add to the adnexal abnormalities frequently described with this syndrome thus characterising the full spectrum of ocular involvement.

Early ophthalmic examination to diagnose and treat refractive errors and strabismus will aid in detection of preventable causes of vision loss. This loss is most likely the result of amblyopia. Vision can improve with treatment but normal acuity was not obtained in most of the affected eyes. The need for aggressive amblyopia treatment, persistent encouragement and support of this treatment, and return visits to monitor compliance are essential to restore or prevent visual loss.

1 Franceschetti A, Klein D. The mandibulofacial dysostosis: a new hereditary syndrome. Acta Ophthalmol (Copenh) 1949; 27: 144-9.
2 McKenzie J, Craig J. Mandibulofacial dysostosis (TreacherCollins syndrome). Arch Dis Child 1955; 30: 391-411.

3 Rogers BO. Berry-Treacher-Collin's syndrome: a review of 200 cases. Br f Plast Surg 1964; 17: 109-13.

4 Treacher Collins E. Case with symmetrical congenital notches in the outer part of each lower lid and defective developmen of the malar bone. Trans Ophthalmol Soc UK 1900; 20: 190.

5 Berry GA. Note on a congenital defect (?coloboma) of the lower lid. Roy Soc London. Ophthalmol Hosp Rep 1889; 12: 255.

6 Wang MF, Millman AL, Sidoti PA, Goldberg RB. Ocular findings in Treacher Collins syndrome. Am $\mathcal{f}$ Ophthalmol 1990; 110: $280-6$.

7 Hurwitz P. Mandibulofacial dysostosis. Arch Ophthalmol 1954; 51: 69-74.

8 Miller MT. Ocular abnormalities in craniofacial malformations. Int Ophthalmol Clin 1984; 24; 143-63.

9 Fries PD, Katowitz JA. Congenital craniofacial anomalies of ophthalmic importance. Surv Ophthalmol 1990; 35: 87-119.

10 Bartley GB. Lacrimal drainage anomalies in mandibulofacial dysostosis. Am f Ophthalmol 1990; 109: 571-4.

11 Cohen MM Jr. An etiologic and nosologic overview of craniosynostosis syndromes. Birth Defects 1975; 11: 137-84.

12 Feingold M, Gellis SS. Ocular abnormalities associated with first and second arch syndromes. Surv Ophthalmol 1968; 14: $30-42$.

13 Converse JM, McCarthy JG, Wood-Smith D. Clinical aspects of craniofacial dysostosis. In: Converse JM, McCarthy JG Wood Smith D, eds. Symposium on diagnosis and treatment of Wood Smith D, eds. Symposium on diagnosis and treatme
craniofacial anomalies. St Louis: Mosby, 1979: 241 .

14 Tessier P. Anatomical classification of facial, cranio-facial and latero-facial clefts. $\mathcal{F}$ Maxillo-Fiacial Surg 1976; 4: 69.

15 Van der Meulen J, Mazzola R, Stricker M, Rapheal B. Classification of craniofacial malformations. In: Stricker $M$ Van der Meulen J, Rapheal B, Mazzola R, eds. Craniofacial malformations. New York: Churchill Livingstone, 1989: 149-309.

16 Caldarelli DD, Hutchinson JG Jr, Pruzansky S, Ingman JL. A comparison of microtia and temporal bone anomalies in hemifacial microsomia and mandibulofacial dysostosis. Cleft Palate f 1980; 17: 103-10.

17 David DJ, Mahatumarat C, Cooter RD. Hemifacial microsomia: a multisystem classification. Plast Reconstr Surg 1987; 80: 525-33.

18 Hertle RW, Quinn GE, Katowitz JA. Ocular and adnexa findings in patients with facial microsomias. Ophthalmology 1992; 99: 114-9.

19 Dixon MI, Read AP, Donnai D, Colley A, Dixon J, Williamson R. The gene for Treacher Collins syndrome maps to the long arm of chromosome 5. Am F Hum Genet 1991; 49: 17-22.

20 Sulik KK, Johnston MC, Smiley SJ, Speight HS, Jarvis BE. Mandibulofacial dysostosis (Treacher Collins syndrome): a new proposal for its pathogenesis. Am f Med Genet 1987; 27 : 359-72.

21 Vermeij-Keers CHR, Mazzola RF, van der Meulen JC, Strickler M. Cerebrocraniofacial and craniofacial malformations: an embryological analysis. Cleft Palate $f$ 1983; 20: tions: an

22 Whitaker LA, Katowitz JA, Jacobs WE. Ocular adnexal problems in craniofacial deformities. Furnal of Maxillofacial Surgery 1979; 7: 55-9.

23 Diamond GR, Katowitz JA, Whitaker LA, Quinn GE, Schaffer DB. Variations in extraocular muscle and structure in craniofacial dysostosis. Am 7 Ophthalmol 1980; 90: 416-8.

24 Hertle RW, Quinn GE, Katowitz JA, Piest KL, Minguini N, Schaffer DA. Visual abnormalities and strabismus in a craniofacial clinic. Suppl. Ophthalmology 1990; 150.

25 Hertle RW, Quinn GE, Minguini N, Katowitz JA. Visual loss in patients with craniofacial synostosis: $\mathcal{F}$ Pediatric Ophthal mol Strabismus 1991; 28: 344-9.

26 Poswillo D. The pathogenesis of the Treacher-Collins syndrome. Br f Oral Surg 1975; 13: 1-22. 